\title{
France urged to head 'Rubbiatron' efforts
}

[PARIS] France's ministry of research has been urged to head an international collaboration to develop ideas drawn up by the physicist Carlo Rubbia for a 'safe' nuclear reactor and in particular to examine using the technology to destroy nuclear waste.

The proposal comes from Claude Birraux, a member of the National Assembly who has represented the Haute Savoie region since 1978. Birraux, a chemical engineer by training, has been the author of a number of reports on nuclear safety produced by the parliament's office of science and technology assessment.

Last November, Rubbia - Nobel prizewinner in 1984 for discovering the $\mathrm{W}$ and $\mathrm{Z}$ particles - presented members of the parliamentary office with proposals for a coupled accelerator-reactor using thorium as fuel. It was dubbed 'Rubbiatron' by the French press.

Rubbia has already received funding from the European Commission for research into his ideas at CERN, the European Laboratory for Particle Physics in Geneva, Switzerland, of which he was formerly director.

The proposed reactor would use an accelerator producing a current of protons, which would bombard molten lead to produce highenergy neutrons. These would be directed at thorium-232 targets, which transform into fissile uranium-233, starting a chain reaction.

According to Rubbia, the system has several advantages over conventional reactor designs. The reactor would remain subcriti$\mathrm{cal}$, and it could be switched off rapidly by cutting the proton beam. Also, replacing thorium with either plutonium or uranium-239 would allow the reactor to burn nuclear waste.

\section{IMAGE \\ UNAVAILABLE \\ FOR COPYRIGHT REASONS}

Ring of promise: Experiments on Carlo Rubbia's proposed reactor ideas at CERN in Geneva.

The production of radioactive actinides would be much lower than with conventional reactors, says Rubbia. The cost of energy production would also be competitive, although the initial costs would be considerable. A prototype 100-MW reactor would cost FFr1 billion (US\$175 million).

But Birraux's report on Rubbia's ideas, published in draft form last month, highlights many potential problems. Many physicists feel that there remain major technical problems with the design of the tungsten 'door' the 'admission window' - by which protons would enter the reactor. This would have to resist high-energy protons and neutrons as well as the corrosive power of molten lead.

The window would have to be replaced once a year, causing difficulties that will need to be taken into account in its design. And there are major uncertainties over the thermohydraulic properties of molten lead, as well as its highly corrosive behaviour.

Birraux says these problems will take time to resolve. "I don't believe, like Rubbia, that a prototype could be achieved within five to six years," he says. But he sees considerable potential in the machine as a way of disposing of nuclear waste. A law passed in 1991 requires research to be carried out on nuclear safety and the burning of nuclear waste, and Birraux argues that this could cover research on the Rubbiatron.

The French government is not due to make a final decision on a waste-disposal technique until 2006, and Birraux considers this gives sufficient time to carry out experiments based on Rubbia's ideas. France currently lacks a proton accelerator, and one built for use in Rubbia's project would have many other uses even if the project itself fails. The Phénix fast reactor is planned to be decommissioned by 2005, after which France will be left without a high-speed neutron source.

Birraux's report therefore recommends that the accelerator should be built, while research should continue on the properties of molten lead, the admission window and thorium cycle. It insists on a practical strategy with clear and specific goals. "We must avoid a second Superphénix story," says Birraux.

Rather than proposing that the French government should contribute directly to Rubbia's efforts, Birraux calls for a wide international collaboration. A Euratom commission is due to discuss whether funding for the project should be included in the European Union's fifth Framework research programme. That commission has produced a report identifying the use of Rubbia's technique to burn actinides as a top priority.

Birraux points to knowledge gained from Russia's experience in using molten lead as a coolant in nuclear submarines, and that by the Paul Scherrer Institute in Switzerland from its high-current accelerators.

A key issue remains who would oversee a collaborative project. France's Atomic Energy Commission already has its Isaac programme studying a coupled accelerator-reactor. Even though this is in its early stages, the organization's experience in nuclear issues would be required. CERN is prohibited from carrying out research related to nuclear energy. Birraux suggests that the research ministry could act as a mediator in helping to encourage cooperation.

Cooperation is certainly important, given the cost involved and the divergence between Rubbia's enthusiasm for a reactor and French interest in more immediately practical goals. Birraux is not totally convinced of Rubbiatron's capacity to provide electricity at competitive rates, and feels that Rubbia may be underestimating the technical difficulties. "It's too soon to know", he says. EricGlover

\section{result in the loss of about a thousand jobs.}

The organization decided last year that it should no longer try to maintain its current up a special commission to draw up approved - for changes needed to keep the viable. the scientific excellence of the academy's institutes", says Keviczky. "This mean of research."

But Keviczky is worried that the general assembly may not be enthusiastic about the formal recognition of the academy's need to contract. "It will take a very strong effort to make this historic decision", he says.

Academy staff numbers have already fallen by more than a third since 1990 as scientists have left the country or joined industry, mostly because of low wages and poor working conditions. Quirin Schiermeier 